\title{
New Media: A Potential Mechanism to Exacerbate Health-Related Disparities
}

\section{Amanda Richardson*}

Director, Research and Evaluation, LEGACY, Washington, USA

The way Americans get their news and information is changing. Newspaper newsrooms are approximately 30\% smaller than in 2000, network news suffered its sixth consecutive year of declines in viewership, and for the first time in 12 years, the audience for cable news fell substantially [1]. As these declines occur, web-based news reading and information gathering has significantly increased. According to 2011 data from the Pew Internet and American Life Project [2], roughly 78\% of American adults are now using the internet, up from $14 \%$ in 1995 . Of these, $76 \%$ say they use the internet to read the news, and $83 \%$ to search for health and medical-related information.

Despite overall increases in internet use, there are still those that lag behind in adoption, namely non-Hispanic blacks and those with lower income and educational attainment [2]. While some reports suggest that this so-called 'digital divide' may be narrowing over time with the increasing adoption of mobile devices and access to broadband [3,4], others have suggested otherwise [5,6]. Even if all groups were assured equal access to technology, the ability to derive equal benefit from its resources may still persist.

This has particular implications for health. The internet is flooded with health- and medical-related news and information, some from reputable sources and others not. So while the internet has the potential to serve as a valuable health-related resource, it may also promote false beliefs, encourage use of non-approved products or services, or foster suspicion of the medical establishment and currently accepted clinical guidelines and practices. Those who benefit from health-related resources on the internet are arguably those with the skills and knowledge to not only access the most reputable news and information sources, but also navigate through sometimes complicated web pages, comprehend the language and terminology, and understand and have the ability to follow through on suggested recommendations. Dr.VishViswanath from the Harvard School of Public Health refers to these as communication inequalities, and along with colleagues has developed The Structural Influence Model of Health Communication to delineate their effect on health [7]. The model theorizes that communication is a critical thread that links social factors such as race/ ethnicity and socioeconomic status to health outcomes. Given that communications plays a central role in promoting healthy behaviors [8-10], inequalities in communication among different subgroups, such as differential access to and use of information channels, attention to health content, and comprehension and capacity to act on relevant information, may result in differential prevention and treatment outcomes [7].

While it has been shown that the majority of Americans receive information, care, or support from a health professional offline [11], online news and information is quickly becoming an important supplement. It is here that minority and vulnerable populations, particularly those of lower education and lower literacy, have a clear disadvantage. Individuals searching for health information online are roughly five times more likely to have a college degree than less than a high school degree, and more than two times more likely to be earning $\$ 75,000$ or more per year as opposed to less than $\$ 20,000$ per year. They are also $30 \%$ less likely to be black as opposed to white [12]. Even those who do use the internet for health-related information suffer a disadvantage as popular health websites such as WedMD.com and Breastcancer.org are written at a $13^{\text {th }}$ and $12^{\text {th }}$ grade level, respectively, and the National Institutes of Health's website is written at the $9^{\text {th }}$ grade level [13]. A qualitative study with low literacy and culturally diverse parents found that some actually intentionally avoided .edu or gov websites because such websites were viewed as too complex [14].

When new information is delivered indiscriminately via the mass media, it is acquired at a faster rate among those of higher socioeconomic status [15]. Our understanding of the mechanisms underlying this process, however, is limited. Given that the wealth gap between white and non-white is widening, with the median wealth of white households now 20 times that of non-Hispanic black households and 18 times that of Hispanic households [16], research is needed to examine the processes which give rise to communication equalities. Given the constant evolution of the media landscape, comprehensive efforts will be needed to ensure that all groups are benefiting equally from health messages on the internet. If not, the rise of new media may serve only to exacerbate already apparent disparities in health.

\section{References}

1. Project for Excellence in Journalism (2011) The State of the News Media 2011 An Annual Report on American Journalism.

2. Pew Internet \& American Life Project (2011) Trend Data.

3. Smith A (2010) Home Broadband 2010. Pew Internet \& American Life Project. Washington, DC

4. Smith A (2010) Mobile Access 2010. Pew Internet \& American Life Project. Washington, DC

5. Lorence D, Park $\mathrm{H}$ (2008) Group disparities and health information: a study of online access for the underserved. Health Informatics Journal 14: 29-38.

6. Lorence D, Park H (2007) Study of education disparities and health information seeking behavior. Cyberpsychol Behav 10: 149-151.

7. Viswanath K, Ramanadhan SR, Kontos EZ (2007) Mass media and population

*Corresponding author: Amanda Richardson, Director, Research and Evaluation, LEGACY, Washington, USA, Tel: 202-454-5571; Fax: 202-454-5599; E-mail: ARichardson@legacyforhealth.org

Received January 06, 2012; Accepted January 06, 2012; Published January 08 , 2012

Citation: Richardson A (2012) New Media: A Potential Mechanism to Exacerbate Health-Related Disparities. J Mass Communicat Journalism 2:e107. doi:10.4172/2165-7912.1000e107

Copyright: ( 2012 Richardson A. This is an open-access article distributed under the terms of the Creative Commons Attribution License, which permits unrestricted use, distribution, and reproduction in any medium, provided the original author and source are credited. 
Citation: Richardson A (2012) New Media: A Potential Mechanism to Exacerbate Health-Related Disparities. J Mass Communicat Journalism 2:e107. doi:10.4172/2165-7912.1000e107

Page 2 of 2

health: a macrosocial view. In: Galea S (ed) Macrosocial Determinants of Population Health. Springer, New York 275-294.

8. Viswanath $\mathrm{K}$ (2006) Public communications and its role in reducing and eliminating health disparities. In: Thomson GE, Mitchell F, Williams MB (eds) Examining the Health Disparities Research Plan of the National Institutes of Health: Unfinished Business. Institute of Medicine, Washington, DC 215-253.

9. Hornik R (2002) Public Health Communication: Evidence for Behavior Change. Lawrence Erlbaum, New York.

10. Smedley B, Stith A, Nelson A (2003) Unequal Treatment: Confronting Racial and Ethnic Disparities in Health. The National Academies Press, Washington, DC.

11. Fox S (2011) The Social Life of Health Information, 2011. Pew Internet \& American Life Project. Washington, DC.

12. Koch-Weser S, Bradshaw YS, Gualtieri L, Gallagher SS (2010) The Internet as a health information source: findings from the 2007 Health Information National Trends Survey and implications for health communication. J Health Commun 3: 279-293.

13. Harvard Public Health Review (2009) Social Threats and Disparities: The Digital Divide.

14. Mackert M, Kahlor L, Tyler D, Gustafson J (2009) Designing e-health interventions for low-health-literate culturally diverse parents: addressing the obesity epidemic. Telemed J E Health 15: 672-677.

15. Tichenor PJ, Donohue GA, Olien CN (1970) Mass media flow and differential growth in knowledge. Public Opinion Quarterly 34: 159-170.

16. Kochhar R, Fry R, Taylor P (2011) Wealth Gaps Rise to Record Highs Between Whites, Blacks, Hispanics. Pew Social and Demographic Trends .Washington, DC. 